\title{
Considering the role and analysing the effectiveness of the media in covering issues of personal finance: the case of Huisgenoot (2007- 2008)
}

Andries Marais

\begin{abstract}
There is a real need for the public to be informed about personal financial matters (such as debt, savings, life insurance and retirement. The media can play an important role in informing and educating the public in this regard. Over the last decade a number of general newspapers and magazines have realised this need. The functions of the media in this regard may involve providing information, education and/or advice. A number of important personal financial topics may be identified for the media agenda. The content of the reporting can be considered in terms of its significance, applicability and complexity. It is difficult to determine the characteristics of the audience. The media can improve its effectiveness in reporting on personal financial matters through such research.
\end{abstract}

Key words: content analysis, media functions, personal finances, topic categories.

\section{Introduction}

Most people have to make many decisions about financial issues during their lifetime. Some of these decisions are very important and can have a major long term impact on the financial wellbeing of the individual and his or her dependents. Few people get any formal training or education about financial matters and most must relay on other sources for information and guidance, quite often from family or friends. For important long term decisions people often use professional financial advisers, but even then a basic knowledge and understanding of financial matters is required. The final decision will always rest with the individual, who should at least be able to evaluate any advice given. There is therefore a real need for the public to be informed about financial matters. In this regard the media can play an important role.

The purpose of this article is to consider the role that the media can play in informing or educating the public in financial matters, to consider the most appropriate research methodology 
for evaluating the effectiveness of the media in this regard and then to apply the methodology to evaluate the success of the reporting on personal financial issues of one specific publication.

\section{Personal finances versus general financial matters}

The focus in this article is on the role of the media in personal finances and not general financial matters. For the purpose of this research my definition of the distinction is as follows.

General financial matters include topics like the global and local economy, financial policy and regulations, trade and industry, inflation, exchange rates, investment markets, business environment, technology, communication, marketing and specific company analysis. These topics have general news value and are covered as such in the general news media. There are a small number of specialist business/financial publications that focus on such general business/financial news but they serve a relatively small audience of readers who are presumably financially astute. The most prominent of these publications are the daily paper Business Day (155 000 readers), weekly magazines Finacial Mail (215 000 readers) and Finweek (74 000 readers). The figures are the average issue readership for the first six months of 2008, from the All Media and Product Study (AMPS) of the South African Advertising Research Foundation (SAARF) (SAARF, 2008).

The second category of personal financial matters is of more direct interest to the general public and this is the area of investigation of this paper. Personal financial matters include topics like savings, investment, life insurance, retirement planning, medical schemes, income tax, personal loans, mortgages, bank overdrafts, credit cards, housing, etc. These topics are of interest to the general public who do not necessarily read the specialist financial publications. Their needs can best be met by the general newspapers and magazines with a wide general audience. Many editors and managers in the media recognise this need and provide for it in the form of regular financial supplements, programmes, columns and articles on personal finance matters.

One of the most prominent personal finance supplements is Personal Finance, which pioneered this field when it first appeared in 1996. It now features countrywide as a weekend supplement in the newspapers of the Independent Newspaper Company (INC), namely Weekend Cape Argus (Cape Town), Saturday Star (Johannesburg), Independent on Saturday (Durban) and Pretoria News, with a combined readership of 775000 (Cameron, 2008). According to Chris Whitfield (2008) editor of Cape Argus, research has shown that Personal Finance is the second most read section of the paper after the sport section. Whitfield states that Personal Finance is clearly fulfilling a real need with the readers and makes a meaningful contribution to the fact that the weekend circulation of the paper is about 40 percent higher than during the week. 
Other large newspapers have followed suit by introducing personal finance supplements, for example Sunday Times with Money, Rapport with Geldsake, and Media24 daily newspapers Die Burger, Beeld and Volksblad (in the Western Cape, Gauteng and the Free State respectively) with their weekend supplement Jou Geldsake. Similarly the weekly magazine Huisgenoot/YOU carries a regular one-page column 'Jou geld/Your money every week, covering a variety of personal finance related matters.

The purpose of this article is to consider the role that the media play through publications such as these in informing or educating the public in personal financial matters.

\section{Approaches to the study of mass communication}

How we think about the power of the media, the media's effects on behaviour, the functions of the media in society and so on, is usually done from a specific theoretical perspective and approach (Fourie, 2007:116). Historically two dominant theoretical research traditions developed in the study of mass communication, namely the positivist and the critical perspectives (Oosthuizen, 1997:3).

In positivist communication research, the methodology followed is quantitative, which is largely empirical or experimental and is based on measurement in the observable world. The data is numerical and the analysis is statistical, which yield objective findings that offer powerful tools for achieving generalised and reliable knowledge (Lemon, 1997:33; McQuail, 2005:63; Fourie, 2007:117).

In the critical paradigm, the methodology is qualitative and the researchers do not believe that there is one objective 'reality' which can be observed and neutrally quantified. The data is verbal and the analysis is interpretative, examining phenomena in a holistic way. Examples of qualitative research include field observation, focus groups, in-depth interviews, case studies and social surveys (Fourie, 2007:145, Lemon, 1997:33).

Whatever the approach, the research process should have the important characteristics of validity, which means that it must represent a true picture of what is studied, and reliability, which means that it must be consistent and possible to replicate (Lemon, 1997:31). The emphasis in quantitative research on the scientific method, strives to ensure objectivity and reliability, but it is often criticised for separating facts from their context (Lemon, 1997:33). The lack of external validity and external reliability is often indicated as a disadvantage of qualitative research (Pitout, 1997:107,113,117).

Most positivist research today is done with some critical interpretation, and most critical research tests its assumptions empirically (Fourie, 2007:145). This fusion of paradigms is called 
triangulation, a term coined by Denzin, according to Mouton and Marais (1988:91). Triangulation use multiple sources of data collection in a research project, to increase the reliability of the results (Lemon, 1997:33), which is the approach used in this article.

\section{The positivistic approach}

The positivistic approach was guided by the classic quotation 'Who says what in which channel to whom with what effect?' of Harold Laswell (Fourie, 1997:121). This first phase of media effect studies believed in strong media effects on a defenceless mass society (Oosthuizen, 1997:7) and the critical question was: 'What does the media do to people?' (Fourie, 1997:236). The second phase of positivist studies under the leadership of Paul Lazerfeld concluded that the media played a more limited role. The two-step-flow model of communication effects recognised the personal influence of opinion leaders, reducing the direct effect of media exposure (Oosthuizen, 1997:7). The question then changed to: 'What do the people do with the media?' which formed the basis for uses and gratifications theory, emphasising how people use the media to gratify certain needs (Fourie, 1997:236).

Positivist research is usually empirical, behaviourist and functionalist, and one of the typical research methods are quantitative content analysis (Fourie, 1997:118). This investigation into the role that the media play (and choose to play) about personal financial matters, and how the public may use the media in this regard, falls largely in the positivist paradigm of functionalism, and also within the uses and gratifications theory. To the extent that the media decides on which topics to discuss in terms of personal financial reporting, agenda setting theory may also be applicable.

\section{Functionalist theory}

According to Oosthuizen (1997:8), functional analysis investigates social phenomena, such as the media, in terms of their consequences for broader society. Therefore this approach corresponds well within the context of the aim of this study.

The functionalist theory views the media as one of the powerful socialisation instruments that contribute to integration, harmony and cohesion in society, through their functions of providing information, entertainment and education (Fourie, 2007:119). This theory depicts the media as self-directing and self-correcting, and has a conservative bias in that the media is seen as more likely to maintain society than to act as a source of major change (McQuail, 2005:97).

The classic functionalist model argues that the main functions of the media in society are to inform and entertain and thereby contribute to cultural growth for individuals and society 
(Fourie, 2007:187). McQuail (2005:97) summarises five basic media functions, namely (a) to inform about events, conditions and relationship and to facilitate progress; (b) to provide correlation by interpreting and commenting on information and events, (c) to encourage continuity of existing culture and common values; (d) to entertain by providing amusement and relaxation, and lastly (c) to mobilise support for social objectives. According to McQuail (2005:97), functionalism is still relevant in framing and answering research questions about the media.

The functions of the media relating to the personal finance issues considered in this article, can most likely be seen in providing information (about financial products, conditions, methods, innovations) and providing correlation (explaining, interpreting and commenting on the information). The purpose of this article is to investigate this view.

\section{Uses and gratification theory}

According to McQuail (2005:425) the aim of uses and gratifications research was to reach a theoretical framework of audience motivations for media use, for which he proposes the following topology: (a) diversion, to escape from daily routine and problems and get emotional release, (b) personal relationships, using the media to keep them company; (c) personal identity, using the media to compare, challenge, confirm themselves and their values and (d) surveillance, to get information about the world, circumstances and issues that can affect them.

For the audience of personal finance media content, surveillance is likely to be an important motive, to get information about the world of personal finance and the related issues. Personal identity may also be a motive, to the extent that advice given may confirm the views and actions of the audience.

According to McQuail (2005:426) the uses and gratifications approach was criticised as too behaviourist and functionalist, and that it failed to predict or explain media choice and use successfully.

\section{Agenda setting theory}

The long term media effect theories assume that the media can affect behaviour over a longer period of exposure (Fourie, 2007:237). Agenda setting theory is one of the prominent long term theories which postulate that the media have a strong impact on our knowledge and understanding of the world that affects our behaviour.

Steinberg (2007:262) sees agenda setting as part of the selection of news stories and the prominence given by the media to the stories. The media select events, topics, issues and individuals they consider to be important and force attention of the public to these matters. The 
public think about, talk about and have feelings about the matters the media choose to publicise, and think these matters are important because of the media attention they receive (McCombs \& Shaw, 1972:177; Steinberg, 2007:262).

The agenda setting hypothesis can be summarised that the press 'may not be successful much of the time by telling people what to think, but it is stunningly successful in telling its readers what to think about' (McCombs et al, 1972:177). This article will consider the agenda setting function of the media in their selection of personal finance topics.

\section{Research methodology}

An appropriate research methodology for evaluating the effectiveness of the media in informing, educating or advising the public in financial matters is considered. Based on interviews with experts, important personal finance issues are identified (to use a benchmark for measuring media coverage) and the role/functions of the media are defined. Certain characteristics of articles on personal finance, for the purpose of content analyis, are also defined. A content analysis of the 'Your Money' column in Huisgenoot/YOU is done as an example of evaluating the success of a publication in the reporting on and meeting the needs of their readers in personal finance matters.

\section{Methodology: in-depth interview}

In considering the role that the media play (and want to play) in informing or educating the public on matters of personal finance, I used in-depth interviews with a small number of editors and journalists involved in this area of journalism.

In-depth interviews can be used as a technique to explore participants' perspectives on a particular issue or phenomenon (Pitout, 1997:112). Hester (1996:186) sees a personal interview as the most effective way to capture in-depth attitude or opinion information, where the interviewer has great flexibility in survey length and structure. Pitout (1997:133) provides guidelines for planning in-depth interviews. The topics to be discussed must be established and the informant must be given the aim of the interview, the expected duration and an undertaking of confidentiality (if required). The advantages of an in-depth interview, according to Wimmer \& Diminick (1991:149), are the wealth of detail and the accurate responses on sensitive issues that it provides, but a big disadvantage is that results are difficult to generalise because of the small non-random sample. The non-standard nature of the interviews also makes the data difficult to analyse (Pitout, 1997:114).

\section{Methodology: Content analysis}


To measure the effectiveness of a publication in fulfilling its role and the possible functions of informing, educating and advising the public on matters of personal finance, a method of content analysis is suggested.

According to Lowrey \& De Fleur (1983:364) content analysis has played a central role in media research, although early efforts were restricted largely to simple classifications and counting. The well known Payne Fund Studies in the early 1930s, for instance, assessed the content of films, classified in ten thematic categories like crime, sex, love, war, etc.(Lowrey et al,1983:36). Later, more elaborate procedures were developed so that reliability and validity could be assessed, indices were devolved for counting different units of content and sampling procedures were adapted accordingly. Content analysis, however, remains a laborious procedure, characterised by the need to make many subjective judgments (Lowrey et al, 1983:364).

From six definitions by main players in the development of quantitative analysis, Neuendorf (2002:10) distilled an encompassing definition of content analysis, which she views as 'the primary message-centered methodology':

Content analysis is a summarizing, quantitative analysis of messages that relies on the scientific method ( including attention to objectivity, intersubjectivity, a priori design, reliability, validity, generalisability, replicability, and hypothesis testing) and is not limited as to the types of variables that may be measured or the context in which the messages are created or presented.

For Neuendorf (2002:14) content analysis must be quantitative, with the goal to provide 'a numerically based summary of a chosen message set'. She disagrees with the view that qualitative content analysis is feasible, but considers empirical qualitative analysis as extremely useful to provide a highly valid source of detailed or 'deep' information about the text. (Neuendorf, 2002:15).

In contrast, Wigston (1997:152) acknowledges the existence of qualitative content analysis. It does not involve physical counting of data, and Wigston considers the approach to be more critical in nature to penetrate the deeper layers of messages, and is preferred for analysing latent messages. He sees the scientific (counting) method of quantitative content analysis as more useful for examining manifest massages

In a linear communication model ('Who says what with what intention by what means with what effect to whom?'), content analysis is specifically linked to the message part ('what') of the process, but it will also give insight into the communicator's intention and the recipient's interpretation, because the method separates messages into their component parts and can make a large variety of variables visible (Wigston, 1997:153). 


\section{Choice of publication for content analysis}

For the content analysis I have decided to consider the column 'Your money' in the general interest family magazine Huisgenoot/YOU. The magazine content includes a mix of real-life drama, glamour, fashion and consumer affair articles as well as recipes, crossword puzzles, home projects, motoring news and sport. It features a number of regular columns aimed at being of service to its readers, assisting them in everyday living and giving useful advice (Viljoen , 2008). The columns include 'Your money', 'Healthy living', 'Ask Dr Adri' (personal advice) 'Ask Debbie' (trauma advice) and 'Beauty'.

My choice was motivated by the very wide circulation of the magazine as well as pragmatic considerations. The weekly column is a one page article of approximately 600 words, covering a single specific topic, of which printed copies for the last two years were readily available from the Media24 archive.

Huisgenoot has a weekday circulation of 332000 (ABC Apr - Jun 08) and a readership of 1889 000 (APMS 2008A), the highest of any South African magazine (SAARF, 2008). The SAARF All Media and Product Study (AMPS) 2008 readership profile of Huisgenoot is as follows:
- $57 \%$ female
$43 \%$ male
- $57 \%$ White
$34 \%$ Coloured
$8 \%$ Black
- $44 \%$ age $16-34$
$32 \%$ age $35-49$
$24 \%$ age $50+$.
- $81 \%$ Afrikaans
12\% English
$7 \%$ black languages
- $24 \%$ LSM 4/5/6
$32 \%$ LSM $7 / 8$,
42\% LSM 9/10
- $42 \%$ working full time
$8 \%$ working part time
$50 \%$ not working

The above can be summarised as predominantly Afrikaans speaking, white or coloured, largely female, with a slight bias towards the younger ages and higher income groups.

YOU, the English translation of Huisgenoot, has a weekly circulation of 205000 (ABC Apr - Jun 08) and its readership of 2172000 (APMS 2008A) is the highest in the country. Its readership profile is as follows:

- $64 \%$ female

- $46 \%$ Black

- $49 \%$ age $16-34$

- $43 \%$ black languages

- $36 \%$ LSM 4/5/6

- $42 \%$ working full time
$36 \%$ male

28\% White

$31 \%$ age $35-49$

39\% English

29\% LSM 7/8

$7 \%$ working part time
26\% Coloured/Indian

$20 \%$ age $50+$.

$17 \%$ Afrikaans

$31 \%$ LSM 9/10

$51 \%$ not working

This can be summarised as predominantly non-white, largely female, with a marked bias towards the younger ages and the lower income groups - significantly different from the readership 
profile of Huisgenoot. The magazines offer exactly the same content to substantially different readership markets.

\section{Sampling}

In social research we cannot investigate every member of a large population and have to base our findings on a sample from the target population (Du Plooy, 1997:54).

In quantitative analysis, various types of probability sampling are used to ensure that samples are representative of the population. Du Plooy (1997:56) lists these as simple random sampling, systematic random sampling, stratified random sampling and cluster random sampling In qualitative analysis non-probability sampling is normally used. This does not represent the population, since each unit does not have a equal chance of being included. Du Plooy (1997:61) lists these methods as availability sampling, purposive sampling, quota sampling and snowball sampling.

In my analysis of the 'Your money' column, the population is the total of all the columns that have appeared in Huisgenoot/YOU since inception in 2005. A systematic random sample over a whole three year period could have been done, but from practical availability reasons I used the year from July 2007 to June 2008, for which paper copies of 50 articles were readily available from the Media24 archive. This is a form of cluster random sampling, selecting a (random) one year period out of a possible three years (i.e. sampling a cluster rather than individual units). It is reasonable to assume that the sample is representative of the population, which is the purpose of sampling.

For the in-depth interviews I used a purposive sample (i.e. selected with previous knowledge of the researcher) of three editors/journalists (only three because of time constraints). The disadvantage of such a non-probability sample is that it is likely to be biased so that the research therefore would not have external validity or reliability (Du Plooy, 1997:64).

\section{Unit of analysis}

In content analysis, the unit of analysis is the item to be categorised and counted. It must be a measurable unit which provides a standard method of analysing the data, and the unit of analysis selected will depend on what is to be studied (Wingston, 1997:157).

Neundorf (2002:20) provides examples of content analysis done on religious television in the USA, based on a randomly selected sample of 81 episodes, using different units of analysis. The study covered five aspects, namely: 
- demography, with the unit of analysis each individual character, measuring a dozen demographic variables (e.g., age, occupation, religious affiliation);

- topics, with the unit of analysis 5-minute time intervals, measuring the presence or absence of 60 specifically defined social, political or religious topics;

- interaction, with the unit of analysis each verbal utterance, coded into one of 20 modes (e.g., offering information, seeking support, attacking, evading);

- communication style, with the unit of analysis each verbal utterance, coded into a variety of characteristics (e.g., mode, social intensity, pace, facial intensity); and

- physical contact, with the unit of analysis each instance of non-accidental physical contact, coded into characteristics (e.g., initiator, recipient, religious touching, anatomical location).

In my research the unit of analysis is the column itself. Weber (1985:23) points out that unless the whole text is relatively short (e.g. a sentence or paragraph), it is difficult to achieve high reliability when coding whole texts. For this reason this analysis does not measure up to the scientific standard of quantitative content analysis as defined by Neuendorf (2002:10).

\section{Identification of categories for content analysis}

In this analysis, the unit of analysis (the column) is categorised according to its topic, four characteristics of the content (function, significance, applicability and complexity) and two characteristics of the target audience (age/income and gender). As pointed out by Berger (1998:25), defining terms in content analysis is critical and what most researchers do is to offer operational definitions of concepts they are investigating. The operational definitions of the characteristics for this analysis are provided below.

\section{Topic of the column}

The first aspect to be analysed is what topics are actually covered by the columnist. The columns are classified according to their content in twelve thematic categories. The categories are based on what was considered to be the most significant personal financial issues, determined by expert opinion obtained through in-depth interviews.

In terms of the agenda setting theory, the media select events, topics and issues they consider to be important and force attention of the public to these matters. This analysis will give an indication of the agenda setting preferences of the journalist/magazine in terms of personal financial issues. 
Apart from the topic, it is suggested that four characteristics of each personal finance article can be deducted from its content, namely the function, financial significance, applicability and complexity. In addition, some demographic characteristics of the target audience are considered.

An analysis of these characteristics should give an indication to what extent and with what effectiveness the publication meets specific needs of specific sections of its audience in terms of personal financial matters.

\section{Characteristics of the column}

\section{Function}

As discussed under 'Functionalist theory', the functional roles that the media can play in relation to personal finance can be defined as providing information, education, advice and warning. These functions are not mutually exclusive and classifying a specific article into a certain function category requires subjective judgement. The classification is done according to the predominant function, but in some cases an article is classified into more than one category.

Information: The article basically provides information (e.g., the impact of the new credit act on home loans).

Education: The article explains general concepts and provides information that will assist in the understanding of general concepts (e.g., explaining concepts like dividend yield and price/earnings ratios, gearing, etc., used in the valuation of company shares listed on the stock exchange)

Advice: $\quad$ The article explains how to organise personal finances and what to do in certain circumstances (e.g. how to draw up a budget, how to react to raising interest rates)

Warning The article gives warning about what not to do or what to avoid, which is a special form of advice (e.g., not to sell shares in a panic if the market falls).

\section{Financial significance}

The significance of a personal finance article is largely determined by its topic and the issue addressed under that topic. It is measured in terms of how important it is for readers to be informed about this topic and what the potential financial consequences of actions in this regard may be, both in size and duration. A topic like Christmas shopping has a rather small or no long term financial impact, while a topic like retirement planning can have a very large and enduring impact. 
In this research the significance of a personal finance article is classified as follows:

Limited: Not much financial involvement required, with limited or short term potential consequences

Average: Reasonable financial involvement required, with some short to medium term potential consequences

High: Substantial financial involvement required, often over an extended period, with serious potential long term consequences

\section{Applicability}

The applicability or reach of an article is defined in terms of how many of the potential readers the subject matter is likely to interest or to affect. A topic like income tax is very generally applicable, while a topic like investing in offshore hedge funds has limited applicability. Cameron (2008) states that he determines the priority of any article in Personal Finance by asking the question: 'How many people will this affect?'

In this research the applicability of a personal finance article is classified as follows:

Limited: Applicable only to a small group of readers (e.g., potential brides)

Average: Applicable to many readers (e.g., all students)

General: Applicable to the large majority of readers.

\section{Complexity}

The complexity of the subject matter covered in an article is defined in the normal meaning of the word and is classified as follows:

Easy: $\quad$ Easy, simplistic topic (e.g., wages for domestic workers)

Average: Generally understandable topic (e.g., retirement planning)

Difficult: Complex topic, little known (e.g., share derivatives)

\section{Characteristics of the audience}

Apart from the characteristics of each article as set out above, some demographics of the target audience may also be deduced (albeit subjectively) from the content of the article. The AMPS readership characteristics include gender, race, age, household income, living standards measure (LSM), language, community, work status, life stage and education (SAARF, 2008). This level

of detail about the target audience for a specific article can obviously not be deduced from its content. 
In terms of the effectiveness of personal finance reporting by a publication, it is suggested that the gender, age and income group of the target audience of each article may be meaningful to deduce from the content of the article. That can then be compared to the AMPS profile of the publication to form an impression of the effectiveness of reaching different audiences.

\section{Age group (correlated with income)}

It is not possible to deduce the age group or the income group at which a specific article is targeted with great accuracy, but some subjective inference can be made. To the extent that people (particularly in the middle and higher income groups) may advance in their careers and income earning potential over their working lifetime, it can be assumed that there is some correlation between age and income. It is suggested that the target readership can be categorised in the following age/income groups:

Young: Applicable to readers with relatively low income, early in career, first purchase of major items, single or newly wed, babies or no children.

Average: Applicable to readers with reasonable income, settled in career, homeowner, married (or divorced), teenage or grown children.

Old: $\quad$ Applicable to readers near, at, or in retirement

All ages Applicable to all readers

\section{Gender}

It is suggested that the target readership of a specific article can be categorised as follows:

Male: $\quad$ Largely applicable to males

Female: $\quad$ Largely applicable to females

All sexes: $\quad$ Applicable to males and females

\section{Defining topic categories for content analysis}

Cameron \& Kruger, product actuaries at Sanlam (a large financial institution involved in insurance, savings, investment, retirement funding and medical aid provision), provided their views on the personal financial issues or topics they considered important for the general public (Cameron, 2008a; Kruger, 2008).

Kruger (2008) provided a preliminary list of topics and Cameron (2008a) included basically the same topics, only with a slightly different order of importance. From this input a list of ten personal financial topic categories was constructed, ranked (albeit subjectively) in declining order of importance by Cameron (2008a). 
During the classification of the Your money articles into these topic categories I considered it necessary to add two additional categories The first was a category for property investment separate from other investments. The second was a category for income/earnings related matters that did not appear on the original list (which concentrated on the expenditure side).

The resulting list of twelve topics for categorising the content of personal financial articles is as follows:

\begin{tabular}{|c|c|c|}
\hline Ranking & Topic category & Description/examples if issues \\
\hline 1. & Debt management & $\begin{array}{l}\text { House mortgage, vehicle finance, hire purchase, } \\
\text { credit/store cards, overdrafts, personal loans, debt } \\
\text { consolidation, debt collectors., sequestration, etc }\end{array}$ \\
\hline 2. & Long term savings & $\begin{array}{l}\text { Primarily retirement provision in pension funds, provident } \\
\text { funds, preservation funds, retirement annuities } \\
\text { Saving for specific purposes e.g. education. }\end{array}$ \\
\hline 3. & $\begin{array}{l}\text { Pension planning (at } \\
\text { retirement) }\end{array}$ & $\begin{array}{l}\text { Options at retirement, in terms of types of pension, } \\
\text { amount of pension taken in cash, taxation, etc }\end{array}$ \\
\hline 4. & $\begin{array}{l}\text { Insurance of life risks } \\
\text { (life assurance) }\end{array}$ & $\begin{array}{l}\text { Life cover, disability cover, income protection, accident } \\
\text { cover }\end{array}$ \\
\hline 5. & $\begin{array}{l}\text { Insurance against } \\
\text { financial loss (short } \\
\text { term insurance) }\end{array}$ & $\begin{array}{l}\text { Household insurance, vehicle insurance, personal } \\
\text { indemnity, etc. }\end{array}$ \\
\hline 6. & Investments & $\begin{array}{l}\text { Asset classes (equity, fixed interest, offshore) } \\
\text { Investment principles (risk vs return, diversification, etc) } \\
\text { Investment vehicles (endowment policies, linked products, } \\
\text { collective investment schemes, etc) }\end{array}$ \\
\hline 7. & Medical aid & Medical and dental expenses and medial schemes \\
\hline 8. & Property investment & $\begin{array}{l}\text { Residential property (own home), investment in property } \\
\text { unit trust }\end{array}$ \\
\hline 9. & Money management & Budgeting, banking, costs \\
\hline 10. & Taxation & Income tax, capital gains tax \\
\hline 11. & Estate planning & Wills, estate duty, trusts \\
\hline 12. & Income & Salaries, increases, promotion, earnings \\
\hline
\end{tabular}


The topics covered by a specific publication can be classified into these categories. Doing this over a period of time would give an indication of how balanced and complete its coverage of the important personal financial topics was over that period.

\section{Research results}

\section{In depth interviews: the role of the media in personal finances}

As previously stated, the functionalist theory views the functions of the media as providing information, entertainment and education (Fourie, 2007:119). McQuail (2005:97) states the five basic media functions as to provide information, correlation, continuity, entertainment and mobilisation.

The functions of the media relating to the personal finance issues in this respect would most likely primarily be in providing information (for example about financial products, market conditions, new innovations, etc) and providing correlation (explaining, interpreting and commenting on the information).

The editors and journalists interviewed had different views on the functions of the media relating to personal finances, particularly in terms of providing information, education and advice. Many of these differences in opinion could probably be related to the very different nature of the two publications they represented, namely Personal Finance and Huisgenoot/YOU.

Bruce Cameron, editor of Personal Finance, strongly feels that the media should play an educational role in terms of personal finance reporting, and saw that as his primary aim when he launched Personal Finance in 1996 (Cameron, 2008b). He argues that the media has a larger responsibility than just providing information, and should be providing education as well as advice. As an example he refers to the need of the public to be able to compare cost charges on different investment products. An effective tool for this purpose is the reduction in yield (RIY) on an investment product. Cameron (2008b) states that the media should first educate their readers about the concept of RIY, explain what it is, how it works and why it provides a reliable basis of comparison. The media should then provide information about the RIY of different products (endowment policies, collective investment schemes, etc) and the RIY of different product providers for a given product. Finally the media could then also provide advice about other aspect to consider in addition to the RIY and should advise them to obtain the services of a professional financial adviser on important long term financial decisions.

Julia Viljoen deputy editor of Huisgenoot/YOU, on the other hand, views the purpose of the media (in terms of the 'Your money' column) as purely to inform readers about financial matters that may affect them (Viljoen, 2008). There is no intention of educating readers and the 
aim is to provide basic information and advice that may be useful. She does not believe that the magazine should create an image of having superior knowledge or of being pedantic. Viljoen (2008) questions a strict distinction between providing information and education, since in providing new information some education may occur. She agrees that it may be worthwhile to consider educating readers about specific topics, for instance by telling them how investments like shares or derivatives work.

According to Viljoen (2008) there is no predetermined plan for topics to be covered in 'Your money', i.e. no planned agenda setting. It is up to the columnist to decide on the topics and submit a list of potential topics to the editor for approval. The one criterion is that there should not be a repeat of a recent topic. Viljoen (2008) questioned whether there are sufficient personal finance topics to keep a column going. Cameron (2008b) on the other hand has never experienced a lack of topics to write about and normally has a problem with what to eliminate.

For Letitia Watson, columnist of 'Your money' in Huisgenoot/YOU, the focus in personal finance reporting is also on providing information (Watson, 2008). She believes that providing useful information would be educational, but the limited length of her column makes it difficult to explain any concept in depth. She believes that financial reporters have a role to make the readers aware of money matters and to make them more money-wise by providing information that they may not have. Her column may contain an element of advice, but in such cases she prefers to quote the opinion of an expert.

Cameron (2008b) stresses that the nature of media advice on personal finances should be generic or general, and that it cannot be specific or personal. The media can advise that it may now be a good time to consider equity investment, but should not advise supporting a specific institution or buying a specific product. Neither can the media give advice that will apply to the individual circumstances of readers. General advice would also include encouragement to take the correct actions (planning for retirement, budgeting properly) and warning about dangers and pitfalls in the market.

Cameron (2008b) believes that the personal finance journalist should always cover topics that make the headlines, but not from a news perspective. A good example would be the news about the recent crisis in the world banking industry. The personal finance journalist would provide background information to the news by explaining what happened in the US mortgage market and how that affected the world financial industry. In such a situation, however, the readers would also require advice on what to do or warning about what not to do, and the financial media has a very important role to play in this regard. Viljoen (2008) agrees that column topics may be 
linked to current events, like the issue of buying or selling a house at a time when increasing interest rates is cooling off the house market.

Cameron (2008b) also believes that the media have an important watchdog role in the financial markets to take up issues on behalf of consumers, where they may be wrongly treated. This may relate to actions by financial advisors, financial institutions, or even the regulators. The media has a responsibility to expose what is wrong, and this may include failure by a regulator to enforce regulations, or shortcomings in the law and regulations. Viljoen (2008) and Watson (2008) agree that this is an important role for the media, including Huisgenoot/YOU, which do have articles on consumer protection from time to time. They do not, however, consider it appropriate content for the 'Your money' column.

As indicated in the discussion on the functional characteristics, a clear distinction between information, education and advice is somewhat problematic because of the overlap between the functions. This problem was also evident from the interviews with the journalists.

\section{Content analysis of Your money column}

The 50 'Your money' articles were classified into the 12 topic categories above, with a $13^{\text {th }}$ category, 'Other', for any article not covered. Classification was fairly straightforward, but an element of subjective judgment was required where articles involved more than one topic. The result was as follows:

\begin{tabular}{|l|c|c|}
\hline \multicolumn{1}{|c|}{ Topic category } & Number of articles & Percentage \\
\hline Debt management & 9 & $18 \%$ \\
\hline Long term savings & 2 & $4 \%$ \\
\hline Pension planning & 3 & $6 \%$ \\
\hline Insurance of life risks & 0 & - \\
\hline Insurance against financial loss & 2 & $4 \%$ \\
\hline Investments & 9 & $18 \%$ \\
\hline Medical aid & 3 & $6 \%$ \\
\hline Property investment & 4 & $8 \%$ \\
\hline Money management & 6 & $12 \%$ \\
\hline Taxation & 2 & $4 \%$ \\
\hline Estate planning & 0 & - \\
\hline Income & 3 & $6 \%$ \\
\hline
\end{tabular}




\begin{tabular}{|l|c|c|}
\hline Other & $7^{*}$ & $14 \%$ \\
\hline Total & $\mathbf{5 0}$ & $\mathbf{1 0 0 \%}$ \\
\hline
\end{tabular}

*1 of these covered several categories

The figures show that the topics covered by the article during a period of one year were not evenly spread over the topics identified as the most important by the experts. Debt management and Investments were given most prominence by the journalist (36\% in total for these two topics), while Life insurance and Estate planning were totally ignored. The topics Long term savings and Pension planning received less attention than warranted by their priority ranking. Some of the articles classified as Other tended to be of limited financial significance in terms of the definitions used in this study and included topics like wages of domestic workers, cost of eating out and unmarried couples moving in together.

Classifying each article according to its function did not require much subjective judgement. If more than one function could be identified, the classification was based on the dominant function. An article, 'The A to $\mathrm{Z}$ of property letting' was clearly only information, while an article 'Your car: residual value or not' contained information about vehicle financing with residual value, and warning against the risks involved. Only nine of the articles included more than one function, e.g. of the 26 articles providing information, four provided information but also contained an element of advice.

\begin{tabular}{|l|l|c|c|}
\hline $\begin{array}{c}\text { Characteristic } \\
\text { of article }\end{array}$ & \multicolumn{1}{|c|}{ Category } & Number of articles & Percentage \\
\hline Function & Information & $26^{*}$ & $52 \%$ \\
& Education & 0 & - \\
& Advice & $18^{* *}$ & $36 \%$ \\
& Warning & $6^{* * *}$ & $12 \%$ \\
\hline$* \quad 4$ included advice & \\
$* * * \quad 2$ included warning & \\
& & & \\
& &
\end{tabular}

Classifying each article into categories of significance, applicability and complexity required a reasonable amount of subjective judgment. Some examples may assist understanding of the process: An article, 'All about trust funds', providing information about inter vivos trusts and testamentary trusts, was classified as having high financial significance, limited applicability (only for people with assets of more than R3 million) and difficult in complexity. An article 'Many happy returns', providing information about income tax was classified as of average significance, generally applicability and average complexity. 


\begin{tabular}{|l|l|c|c|}
\hline $\begin{array}{c}\text { Characteristic of } \\
\text { article }\end{array}$ & \multicolumn{1}{|c|}{ Category } & Number of articles & Percentage \\
\hline Significance & Limited & 20 & $40 \%$ \\
& Average & 21 & $42 \%$ \\
& High & 9 & $18 \%$ \\
\hline Applicability & Limited & 16 & $32 \%$ \\
& Average & 24 & $48 \%$ \\
& General & 9 & $18 \%$ \\
\hline Complexity & Easy & 28 & $26 \%$ \\
& Average & 9 & $56 \%$ \\
& Difficult & & $18 \%$ \\
\hline
\end{tabular}

Classifying each article according to the characteristics of its target audience required substantial subjective judgment. A small number of articles were clearly meant for young people and/or people with limited income, (like an article 'Save money wisely', about paying small premiums for funeral cover from a savings account) or for older people and/or people with substantial wealth (like an article 'Protect your capital', about accumulated retirement benefits). Most articles were targeted at the 'average' reader of say between ages 25 and 50 with a reasonable income, or to all age and income groups.

Classification according to gender proved problematic. Some decades ago it may have been more possible to classify the subject matter of a specific financially related article to a specific gender, based on the traditional gender roles of the male as breadwinner, responsible for most major financial decisions, and the female as homemaker. Today these gender roles are no longer valid and with two (questionable) exceptions, all articles could relate to both sexes.

\begin{tabular}{|l|l|c|c|}
\hline $\begin{array}{c}\text { Characteristic } \\
\text { of audience }\end{array}$ & Category & Number of articles & Percentage \\
\hline Age / Income & Young & 7 & $14 \%$ \\
& Average & 28 & $56 \%$ \\
& Old & 3 & $6 \%$ \\
& All ages & 14 & $28 \%$ \\
\hline Gender & Male & 1 & $2 \%$ \\
& Female & 1 & $2 \%$ \\
& All sexes & 48 & $96 \%$ \\
\hline
\end{tabular}

\section{Discussion of analysis}


Measured against the list over the sample period of one year Your money did not adequately cover all the important topics identified by this study and covered only two topics extensively.

In terms of possible functions, 'Your money' concentrated on providing information (in just more than half the cases) and did not play any role in providing education, which is consistent with the view of the editor (Viljoen, 2008). The limited length of the column makes it difficult to explain any concept in depth which restricts the educational potential (Watson, 2008). Almost half the articles provide advice (what to do) or warning (what not to do) which is a meaningful function, provided the content has sufficient significance and applicability.

In terms of the content characteristics, the number of articles with limited significance (40\%) is rather high. If the magazine merely wants to provide entertaining content this may be acceptable but if their aim is be of service in informing their readers they may want to reconsider this aspect. The articles with limited applicability (32\%) are also rather high. This may have an effect on the number of people reading the column, which, according to a survey in 2006 was about $55 \%$ of the total readership (Viljoen, 2008). The number of articles with high significance (18\%) and general applicability (18\%) is rather low. The easy or average level of complexity ( $82 \%$ of the articles) is probably reasonable for the readership of Huisgenoot/YOU.

The classification of the articles in terms of the characteristics of the target readership did not yield very meaningful results and cannot effectively be correlated with the AMPS readership profile of the magazines as was envisaged.

\section{Possible further research}

In terms of topics covered, it may be possible to refine and improve the list of topic categories through further research, involving more opinions.

A similar analysis of other publications/supplements (like Personal Finance, Jou Geldsake, Money) would yield a more comprehensive picture of the role and functions that the media play in terms of personal finance matters and the extent to which the needs of the public are met. Such analyses would require more extensive sampling techniques.

\section{Conclusion}

In terms of its functions, the media have a definite role to provide information about personal financial matters. For a very large part of the public, the media are their main source of information about financial markets and personal financial issues, and the media must accept this responsibility. 
There are different opinions about the role or responsibility of providing education on personal finance matters. The nature of the information provided may be educational, particularly if the information is of a general background nature rather than news or event related. In addition, the media can provide meaningful advice on personal finances to its audience and warnings against pitfalls. Each publication could proactively define the information/ education/advice function that it wants to fulfil.

For optimum effectives in achieving its defined role, a publication could set a balanced agenda of topics, to ensure meaningful coverage of all important aspects over time, and some measurement of their achievement, such as this analysis, could assist in the process.

The suggested analysis of the characteristics of the content over time may assist the editor in determining whether the publication is successful in meeting the needs of its specific target audience.

\section{Author details}

Andries Marais

MCT Capstone Project

\section{References}

Berger, A.A. 1998. Media research techniques. Thousand Oaks, London, New Delhi: Sage.

Cameron, B. 2008a. (Ed.) Personal finance. Telephone interview about personal finance topics. 2008-11-23. Notes available from the author.

Cameron, B. 2008b. (Ed.) Personal finance. Telephone interview about media functions in respect of personal finance. 2008-11-11. Notes available from the author.

Fourie, P.J. (Ed). 2007. Media studies: media history, media and society (2nd ed.). Cape Town: Juta.

Grossberg, L.,Wartella, E., Whitney, D.C. \& Wise, J.M. 2006. Media making: mass media in a popular culture. Thousand Oaks, London, New Delhi: Sage.

Hester,E.L. 1996. Successful marketing research. New York, Chichester, Brisbane, Toronto, Singapore:John Wiley \& Sons.

Kruger, E. 2008. Telephone interview on 24 October 2008. 
Lowrey, S.A. \& De Fleur, M.L. 1983. Milestones in mass communication research: media effects. New York: Longmans.

Lemon, J.1997. The research process. In G.M. du Plooy (ed) Introduction to communication: Course Book 2: communication research. 28-47. Cape Town: Juta.

Mouton, J. and Marais, H.C. 1988. Basic concepts in the methodology of the social sciences. Pretoria: HSRC Publications.

McQuail, D. 2005. McQuil's mass communication theory ( $5^{\text {th }}$ ed). Thousand Oaks, London, New Delhi: Sage.

McCombs, M.E. and Shaw, D.L. 1972. The agenda-setting function of mass media. Public Opinion Quarterly, (3):176-187.

Neuendorf, K.A. 2002. The content analysis guidebook. Thousand Oaks, London, New Delhi: Sage.

Oosthuizen, L.M..1997. A brief history of communication research. In G.M. du Plooy (ed) Introduction to communication: course book 2: communication research. 1-27. Cape Town: Juta.

Pitout, M. 1997. Field research in communication, In G.M. du Plooy (ed) Introduction to communication: course book 2: communication research. 104-125. Cape Town: Juta.

SAARF. 2008. Website of South African Advertising Research Foundation, www.saarf.co.za. Accessed 28 October 2008.

Steinberg, S. 2007. An introduction to communication studies. Cape Town. Juta.

Viljoen, J. 2008.Deputy Editor, Huisgenoot/YOU. Personal interview on 30 October 2008. Notes available from the author.

Watson, L. 2008. Columnist, Huisgenoot/YOU. Telephone interview on 11 November 2008. Notes available from the author.

Weber, R.B. 1985. Basic content analysis. Newbury Park, London, New Delhi: Sage. 
Wigston, D.J. 1997. Content analysis in communication research. In G.M. du Plooy (ed) Introduction to communication: course book 2: communication research. 151-170. Cape Town: Juta.

Wimmer, R.D. and Dominick, J.R. 1991. Mass media research: an introduction $\left(3^{\text {rd }}\right.$ ed) Belmont, Calif: Wadsworth. 